\title{
Non-biodegradable polymer particles for drug delivery: A new technology for "bio-active" restorative materials
}

\author{
Satoshi IMAZATO ${ }^{1}$, Haruaki KITAGAWA ${ }^{1}$, Ririko TSUBOI ${ }^{1,2}$, Ranna KITAGAWA ${ }^{3}$, Pasiree THONGTHAI ${ }^{1}$ \\ and Jun-ichi SASAKI ${ }^{1}$ \\ ${ }^{1}$ Department of Biomaterials Science, Osaka University Graduate School of Dentistry, 1-8 Yamadaoka, Suita, Osaka 565-0871, Japan \\ ${ }^{2}$ Division for Interdisciplinary Dentistry, Osaka University Dental Hospital, 1-8 Yamadaoka, Suita, Osaka 565-0871, Japan \\ ${ }^{3}$ Department of Restorative Dentistry and Endodontology, Osaka University Graduate School of Dentistry, 1-8 Yamadaoka, Suita, Osaka 565-0871, \\ Japan \\ Corresponding author, Satoshi IMAZATO; E-mail: imazato@dent.osaka-u.ac.jp
}

To develop dental restorative materials with "bio-active" functions, addition of the capability to release active agents is an effective approach. However, such functionality needs to be attained without compromising the basic properties of the restorative materials. We have developed novel non-biodegradable polymer particles for drug delivery, aimed for application in dental resins. The particles are made using 2-hydroxyethyl methacrylate (HEMA) and a cross-linking monomer trimethylolpropane trimethacrylate (TMPT), with a hydrophilic nature to adsorb proteins or water-soluble antimicrobials. The polyHEMA/TMPT particles work as a reservoir to release fibroblast growth factor-2 (FGF-2) or cetylpyridinium chloride (CPC) in an effective manner. Application of the polyHEMA/ TMPT particles loaded with FGF-2 to adhesives, or those loaded with CPC to resin-based endodontic sealers or denture bases/crowns is a promising approach to increase the success of the treatments by conferring "bio-active" properties to these materials to induce tissue regeneration or to inhibit bacterial infection.

Keywords: Restorative materials, Resins, Drug delivery, Bio-active, Polymer

\section{INTRODUCTION}

The improvement of the basic properties of dental restorative materials, such as their mechanical, physical, aesthetic, and bonding properties, has been dramatic, and the current materials on the market show excellent clinical performance. Therefore, a target of their advancement is being shifted to exhibition of "bio-active" functions to prevent primary/secondary diseases or promote healing of surrounding tissue. Several properties can be proposed as useful "bio-active" functions for restorative materials. One major approach involves addition of "bio-protective" effects such as control of bacterial infection ${ }^{1,2)}$, strengthening of the tooth substrate ${ }^{3,4)}$, prevention of demineralization ${ }^{2,5)}$, or protection of interfacial deterioration ${ }^{6-8}$. The other approach involves conferring "bio-promoting" effects such as remineralizing effects ${ }^{9,10)}$, control of inflammation, or promotion of tissue regeneration ${ }^{11}$.

The most common way to make materials "bioactive" is the addition of the capability to release specific agents. However, the incorporation of active agents directly into dental restorative materials has several drawbacks. First, control of the release kinetics is difficult. To attain clinical effectiveness, it is important to have appropriate release of the agent to suit the environment in which the materials are used. Secondly, as the release of the agent occurs, the materials become porous and their mechanical properties decrease over

Color figures can be viewed in the online issue, which is available at J-STAGE.

Received May 11, 2017: Accepted May 15, 2017

doi:10.4012/dmj.2017-156 JOI JST.JSTAGE/dmj/2017-156 time. Thirdly, in the case of resinous materials, the incorporation of additives may compromise the curing of resins and hamper their integrity for permanent restoration. These are critical problems since dental restorative materials used to artificially recover lost tissue need to have high mechanical properties, physical and chemical stability, or to strongly bond to adherend.

The application of drug delivery systems is considered to be useful to overcome the problems mentioned above. In particular, for resin-based restorative materials, the use of a polymer-based carrier containing the active agents is effective. In the past, a variety of polymers, such as cellulose ${ }^{12)}$, gelatin ${ }^{13)}$, polysaccharide ${ }^{14)}$, polyethylene glycol $^{15}$, or $\operatorname{poly}(2$ hydroxyethyl methacrylate) (polyHEMA) ${ }^{16-19)}$, have been reported as carriers for drug delivery. These polymers form biocompatible hydrogels with excellent water absorbability to facilitate the uptake of therapeutic agents. However, most of them are targeted for regenerative therapy and degrade to release the agent in human bodies. Accordingly, they are not applicable for dental materials used for permanent restoration.

In need of non-biodegradable carrier which is stable even after the active agents leach out (Fig. 1), we newly developed non-biodegradable particles for the delivery of water-soluble agents ${ }^{20,21}$. These particles are made using methacrylate polymers and are compatible with any type of resin used for restorative treatments. In the present paper, the effectiveness of this novel polymer particle as a carrier of growth factors and antimicrobials is summarized. The possible application 

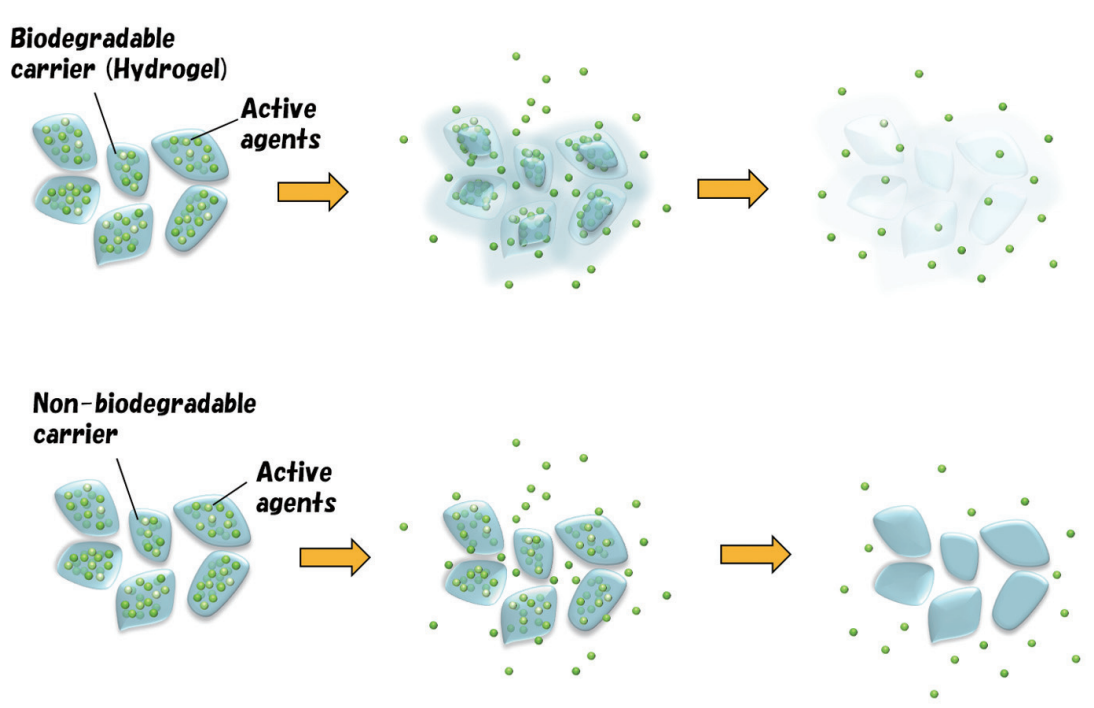

Fig. 1 Schematic diagram of biodegradable and non-biodegradable polymer particles for drug delivery.

of the polymer particles for various restorative materials is also addressed.

\section{DESIGNING NON-BIODEGRADABLE POLYMER PARTICLES FOR DRUG DELIVERY}

Non-biodegradable methacrylate-based polymer particles Among the several methacrylate monomers used for dental restorative materials, HEMA is highly hydrophilic ${ }^{22,23)}$ and a candidate to fabricate particles to carry water-soluble agents. However, a homo-polymer made of HEMA is not completely non-biodegradable ${ }^{19}$. In addition, HEMA-polymer easily aggregates and is difficult to grind into particles. Therefore, we designed a new polymer by combining HEMA and a cross-linking monomer trimethylolpropane trimethacrylate (TMPT, Fig. 2). The HEMA/TMPT binary resin system forms a cross-linked structure and provides a solid polymer that can be pulverized through milling.

We fabricated five types of polymer, by mixing HEMA and TMPT at different weight ratios (Table 1). The mixture of HEMA and TMPT was polymerized using $0.5 \%$ benzoyl peroxide by heating at $120^{\circ} \mathrm{C}$ for 2 $\mathrm{h}$ and then under diminished pressure $(-0.1 \mathrm{MPa})$ for $16 \mathrm{~h}$. The polymerized resin was ground into particles with an average diameter of 500-550 $\mu \mathrm{m}$ using a mill, and washed through immersion in distilled water for $48 \mathrm{~h}$. Figure 3 shows the 90\% HEMA/10\% TMPT polymer particles prepared. The particles are colorless, transparent, and have irregular shapes.

\section{Characterization of the polyHEMA/TMPT particles}

The water absorbability, hydrophobicity, and surface electric charge of the five polymer particles fabricated are summarized in Table 1. The average water absorption ratio ranged from 5.5-21.6\%. An increase in the HEMA content clearly resulted in greater water absorbability,
A<smiles>C=C(C)C(=O)OCCO</smiles>

B<smiles>C=C(C)C(=O)OCC(CC)(CC)COOC(=O)C(=C)C</smiles>

Fig. 2 The monomers used to fabricate the nonbiodegradable polymers.

(A) 2-hydroxyethyl methacrylate (HEMA). (B) trimethylolpropane trimethacrylate (TMPT).

indicating that the particles show water absorbability based on the hydrophilic nature of HEMA.

Interestingly, when the $H$-index ${ }^{24,25}$ of each polymer was measured, the polymers with higher ratios of HEMA showed greater hydrophobicity (Table 1). While the polymers with a greater HEMA content can contain more water because of the hydrophilic hydroxyl group, the alkyl chains of the polymerized HEMA in the network possibly act to provide a hydrophobic characteristic.

HEMA possesses an anionic character, which is present in its polymeric form via the polar hydroxyl 
Table 1 Water absorbability, hydrophobicity, and surface electric charge of polyHEMA/TMPT particles

\begin{tabular}{ccccc}
\hline Abbreviation & $\begin{array}{c}\text { HEMA/TMPT } \\
(\text { wt\% })\end{array}$ & $\begin{array}{c}\text { Water absorbability } \\
\text { (Water absorption ratio, })\end{array}$ & $\begin{array}{c}\text { Hydrophobicity } \\
(H \text {-index })\end{array}$ & $\begin{array}{c}\text { Surface electric charge } \\
(\text { Zeta potential, mV) }\end{array}$ \\
\hline H10 & $10 / 90$ & $5.5 \pm 2.8$ & $1.00 \pm 0.03$ & $-27.9 \pm 1.2$ \\
H30 & $30 / 70$ & $12.7 \pm 4.5$ & $0.99 \pm 0.02$ & $-31.0 \pm 0.1$ \\
H50 & $50 / 50$ & $13.3 \pm 5.2$ & $1.09 \pm 0.04$ & $-25.2 \pm 0.2$ \\
H70 & $70 / 30$ & $19.7 \pm 1.6$ & $1.17 \pm 0.04$ & $-26.1 \pm 0.8$ \\
H90 & $90 / 10$ & $21.6 \pm 2.5$ & $1.30 \pm 0.07$ & $-25.8 \pm 1.8$ \\
\hline
\end{tabular}

Water absorbability was determined by measuring the weight of the hydrogel particles immersed in water for 4 days at $25^{\circ} \mathrm{C}$. Water absorption ratio $(\%)=\left(\mathrm{W}_{\mathrm{b}}-\mathrm{W}_{\mathrm{a}}\right) / \mathrm{W}_{\mathrm{a}} \times 100$, where $\mathrm{W}_{\mathrm{b}}$ and $\mathrm{W}_{\mathrm{a}}$ are the weight of polymer particles before and after storage in water, respectively. To assess hydrophobicity, $100 \mathrm{mg}\left(\mathrm{W}_{\mathrm{d}}\right)$ of the hydrogel particle was immersed in $1 \mathrm{~mL}$ of distilled water or aqueous 70 vol\% isopropanol for $36 \mathrm{~h}$, and the swollen weight $\left(\mathrm{W}_{\mathrm{s}}\right)$ was measured. The equilibrium mass swelling ratio (q) in solvent $\times\left(\mathrm{I} 70\right.$ : $70 \mathrm{vol} \%$ isopropanol, $\mathrm{H}_{2} \mathrm{O}$ : distilled water) was calculated as: $\mathrm{q}_{\mathrm{x}}=\mathrm{W}_{\mathrm{s}} / \mathrm{W}_{\mathrm{d}}$, and the $H$-index was determined as: $H=\mathrm{q}_{\mathrm{I} 70} / \mathrm{q}_{\mathrm{H} 2 \mathrm{O}}$.

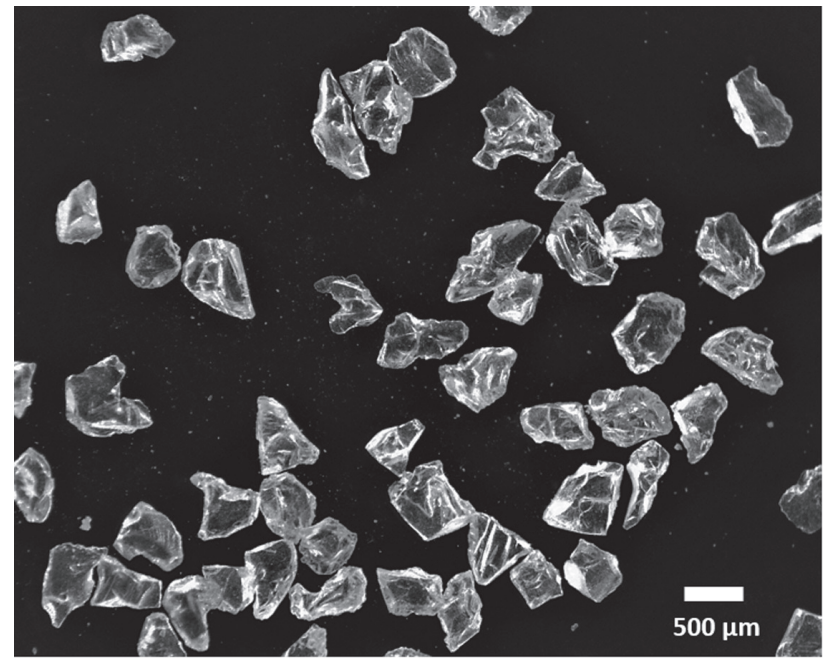

Fig. 3 PolyHEMA/TMPT particles (H90).

groups ${ }^{26,27)}$. The zeta potential of each polymer particle was measured, and all five polymers presented a negative surface charge but their charges were not significantly different (Table 1).

\section{Cytocompatibility of polyHEMA/TMPT particles}

To assess the toxicity of the polyHEMA/TMPT particles to cells, mouse calvaria-derived osteoblast-like cells (MC3T3-E1 cells) were cultured with the particles. Through observations using a scanning electron microscope, the cells were found to spread well on the surface of the particles and exhibited spindle or polygonal shapes after a 3-day culture period. A Live/ Dead staining examination revealed that the cells below and around the polymer particles were all alive. The polyHEMA/TMPT particles fabricated have high polymerization rates and no release of unpolymerized HEMA or TMPT from the particles after the washing procedure was detected.

\section{EFFECTIVENESS AS CARRIERS OF GROWTH FACTORS}

It is well known that growth factors are important molecules to promote tissue regeneration, and a lot of research to utilize growth factors for regenerative therapy has been conducted in the field of dentistry. A promising concept involves combining growth factors with restorative materials to make them "biopromoting". However, since growth factors are proteins, simply adding them to restorative materials is not recommended because of the following reasons; i) dental restorative materials consist of various components and some ingredients may impair the action of growth factors; ii) proteins are large molecules and may hamper setting or curing of the materials. In addition, the release of large molecules can deteriorate the materials as a function of time; iii) proteins are sensitive to thermal conditions. Especially in the case of resinbased materials, the heat generated by polymerization may denature proteins. To exclude these problems and obtain release in an effective manner, we attempted to use polyHEMA/TMPT particles as a carrier vehicle for growth factors ${ }^{21)}$.

\section{Loading and release of model protein}

To investigate the feasibility of polyHEMA/TMPT particles as a protein reservoir, the uptake of protein by $90 \%$ HEMA/10\% TMPT-polymer particles was first investigated using bovine serum albumin (BSA) as a model protein. When the polymer particles were immersed in FITC-labeled BSA solution at $500 \mu \mathrm{g} / \mathrm{mL}$ for $24 \mathrm{~h}$ and observed using confocal laser scanning microscopy (CLSM), adsorption of BSA onto the particle surface was clearly observed (Fig. 4). Such BSA-loaded polymer particles released BSA into distilled water at least up to 14 days. The release pattern demonstrated an initial burst and a gradual decrease thereafter, 
indicating that BSA was mostly adsorbed to the outer surface layer of the particles.

\section{Loading and release of fibroblast growth factor-2 (FGF-2)}

FGF-2 is widely used to accelerate wound healing ${ }^{28,29)}$. FGF-2 promotes the proliferation of various types of cells such as vascular endothelial cells, chondrocytes, osteoblasts, and mesenchymal stem cells ${ }^{30-33)}$. It also stimulates angiogenesis and tissue development ${ }^{28,34)}$. Based on the outstanding clinical outcome of FGF2 for periodontal regeneration ${ }^{35)}$, Regroth ${ }^{\circledR}$ (Kaken Pharmaceutical, Tokyo, Japan), of which the main active ingredient is recombinant human FGF-2, was launched on the market recently, as the world's first pharmaceutical for periodontal regeneration. Therefore, we chose FGF-2 as the growth factor to be loaded into the polyHEMA/TMPT particles.

To load FGF-2, the polymer particles were immersed in FGF-2 solution (Fiblast ${ }^{\circledR}$, Kaken Pharmaceutical) at $500 \mu \mathrm{g} / \mathrm{mL}$ and incubated for $24 \mathrm{~h}$. FGF-2 uptake by the polymer particles was achieved using this procedure, at a

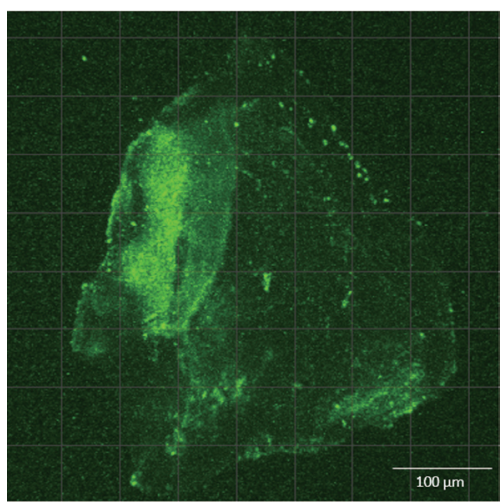

Fig. 4 Loading of BSA into polyHEMA/TMPT particles (CLSM image using FITC-labeled BSA).

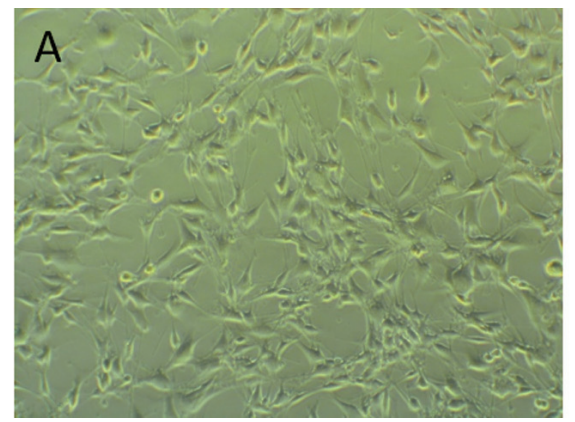

$16.3 \%$ adsorption ratio. When the FGF-2-loaded particles were immersed in distilled water, they showed a similar release profile as that of the BSA-loaded particles. After an initial discharge of the large amount during the first $12 \mathrm{~h}$, a continuous release of a small amount of FGF2 was observed for up to 14 days. However, the initial burst release was greater for FGF-2 compared with that of BSA. This is probably because of the difference in the molecular size of BSA and FGF-2. The size of FGF2 and $\mathrm{BSA}$ are 17 and $67 \mathrm{kDa}$, respectively, and the average diameter is 3-4 $\mathrm{nm}$ for FGF-2 ${ }^{29)}$ and 7-9 $\mathrm{nm}$ for $\mathrm{BSA}^{36)}$. For the release of proteins based on the simple mechanism of water diffusion, smaller sized molecules appear to be easily desorbed from the polyHEMA/TMPT particles.

Effects of FGF-2-loaded polymer particles on osteoblasts To examine if the activity of FGF-2 is maintained after being loaded into the particles, samples of eluates from FGF-2-loaded polymer particles into culture medium (alpha-MEM) were collected periodically and MC3T3-E1 cells were cultured in the presence of those eluates. Cell proliferation was significantly promoted by the eluates (Fig. 5) at all collection periods up to 14 days. The FGF2 released into the medium from the polymer particles was confirmed as maintaining its activity.

\section{Application of FGF-2-loaded polymer particles to restorative materials}

The most common "bio-promoting" material currently used in restorative dentistry is mineral trioxide aggregate (MTA). MTA is a type of calcium silicate cement and is used for various treatments such as direct pulp capping, root-end filling, root canal filling, perforation repair, and apexogenesis ${ }^{37,38)}$. However, the application of dental adhesive resins is also expanding to include various treatments such as restoration of fractured roots $^{39-42)}$, root-end fillings ${ }^{43)}$, or perforation sealing ${ }^{44)}$. Among a plethora of dental adhesive resins, a 4-methacryloxyethyl trimellitate anhydride (4META)/methyl methacrylate (MMA)-based resin is

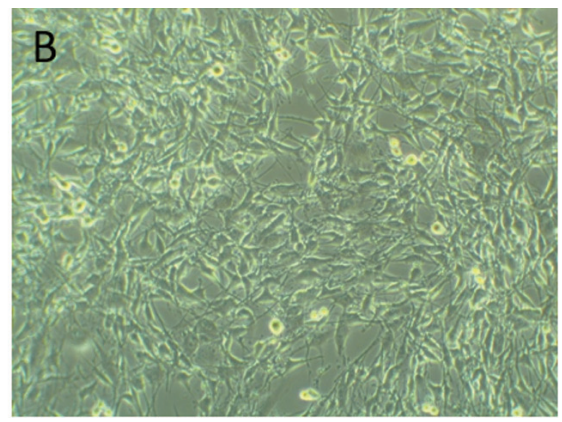

Fig. 5 Promotion of proliferation of MC3T3-E1 cells by the eluates from FGF-2-loaded polymer particles.

Phase contrast microscopy image of MC3T3-E1 cells cultured in the presence of the eluates from (A) the control polymer particles without FGF-2 loading and (B) the particles loaded with FGF-2. 
highly biocompatible, and exhibits excellent bonding and sealing capabilities in wet conditions ${ }^{45}$. Our study demonstrated that osteoblastic cells could proliferate well on cured 4-META/MMA-based resins and the differentiation of pluripotent mesenchymal precursor cells was not hampered ${ }^{46,47)}$. Considering these advantages, the commercial 4-META/MMAbased adhesive resin sold as Super Bond $C \& B^{\circledR}$ (SB; Sun Medical, Moriyama, Japan) is clinically used to treat fractured roots. However, conventional adhesive resins including SB have no ability to promote tissue healing and a favorable prognosis cannot be expected for cases with severe damage of surrounding tissue ${ }^{40)}$. In some cases, incomplete healing has been reported for the bonding of fractured roots with adhesives because of insufficient regeneration of periodontal tissue ${ }^{48)}$. To increase the success rate of treatments using adhesive materials, it is beneficial to provide the ability to release FGF-2.

It has already been demonstrated that the heat generated by the polymerization of SB is not in the range to influence protein $s^{49}$. The temperature inside the adhesive during polymerization does not reach $41^{\circ} \mathrm{C}$, which is enough low to maintain the structure and function of FGF-2. Unpolymerized 4-MET or MMA released from the cured SB had no negative influence on the ability of FGF-2 to promote the proliferation of osteoblast-like cells ${ }^{49}$. We have confirmed that FGF2 released from SB combined with FGF-2-loaded polyHEMA/TMPT particles could promote osteoblastic proliferation. The effectiveness of an experimental adhesive containing FGF-2-loaded particles, in terms of tissue regeneration in vivo, is currently under investigation.

\section{EFFECTIVENESS AS CARRIERS OF ANTIMICROBIALS}

Many dental diseases are caused by the oral microbiome, and restorative materials with antimicrobial effects could be useful for preventing such infectious diseases. A conventional approach to provide dental restorative materials with infection control abilities is to incorporate water-soluble antimicrobials and enable their release in a wet environment $t^{50)}$. However, the duration of the antimicrobial effects produced using this method is limited to a short period and continuous delivery of the agents is not possible. Aiming at achievement of reconstructive materials which exhibit long-lasting antimicrobial effects, we incorporated non-biodegradable polyHEMA/TMPT particles into resin-based materials as reservoirs for water-soluble antimicrobials. Since synthetic antimicrobials are more stable compared with proteins, it is possible to load them into polyHEMA/TMPT particles using two different methods. One method is similar to that used for growth factors; i.e. immersion of the particles into an aqueous solution of the antimicrobial to facilitate uptake. The other method is to add antimicrobials into the HEMA/TMPT monomer mixture and cure it to produce polymers.

Loading of cetylpyridinium chloride using the immersion method

Cetylpyridinium chloride (CPC), a quaternary ammonium compound, is highly soluble in water, and is frequently incorporated in oral rinses or tooth pastes. CPC has a strong antimicrobial activity against oral bacteria and fungi ${ }^{51-55)}$, and was chosen as the antimicrobial to be loaded into the polymer particles.

To load CPC using the immersion method, the polyHEMA/TMPT particles were placed into $30 \mu \mathrm{L}$ of $\mathrm{CPC}$ aqueous solution at $500 \mu \mathrm{g} / \mathrm{mL}$ (total amount of $\mathrm{CPC}=15 \mu \mathrm{g}$ ) and stored for $24 \mathrm{~h}$. The particles were washed in water to remove loosely bound CPC. The polymer particles with HEMA at $50 \%$ or more (H50, H70, H90) demonstrated greater adsorption of CPC than the particles with HEMA at $30 \%$ or less (H10 and H30). Especially, H70 and H90 demonstrated adsorption at more than $97 \%$ (Fig. 6).

However, the release profile of CPC was totally different among the five CPC-loaded particles (Fig. 6). It was found that more than $91 \%$ of the CPC adsorbed to the $\mathrm{H} 10$ and $\mathrm{H} 30$ particles was rapidly released within $24 \mathrm{~h}$. On the contrary, only a small amount of adsorbed CPC $(<4 \%)$ was released from H70 and H90 particles, and most of the CPC remained trapped within the particles. The particles comprising 50\% HEMA $/ 50 \%$ TMPT (H50) showed the largest amounts of release (Fig. 6). As for the release duration, H50 showed release over $48 \mathrm{~h}$, the longest period of release among the five particles.

To analyze the binding mechanism of $\mathrm{CPC}$ to polyHEMA/TMPT, Triton X-100 or $\mathrm{NaCl}$ solution was used as an elution medium and the release of CPC was evaluated. Because Triton X-100 hinders hydrophobic interaction ${ }^{56,57)}$, CPC adsorbed to polymers through hydrophobic interaction is desorbed by this surfactant. $\mathrm{An} \mathrm{NaCl}$ solution is effective to assess the involvement of electrostatic interaction in the binding of CPC to polyHEMA/TMPT since CPC is cationic and shows strong interaction with negatively charged substances ${ }^{27)}$.

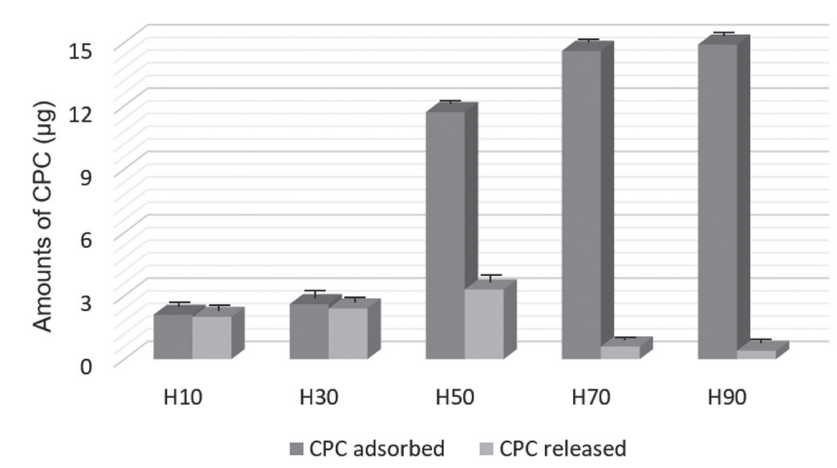

Fig. 6 Total amounts of CPC adsorbed to the polymer particles and released into water within $48 \mathrm{~h}$. 
The results indicate that almost all the loaded CPC was released into Triton X-100 from all the polymer particles, while the adsorbed CPC was not desorbed by the $\mathrm{NaCl}$ solution. These results indicate that CPC binds to the frame of the HEMA/TMPT polymer mainly through hydrophobic interactions.

The loading of CPC and its release from polyHEMA/ TMPT can be explained by the state of CPC, polymer mesh sizes, and the hydrophobicity of the polymer as shown in Fig. 7. As a cationic surfactant, CPC forms micelles at concentrations above $322 \mu \mathrm{g} / \mathrm{mL}^{58)}$. Since the polymers were immersed into a $500 \mu \mathrm{g} / \mathrm{mL} \mathrm{CPC}$ solution, CPC in the small micellar state was taken up by the polymers. The average size of such CPC micelles is approximately $1 \mathrm{~nm}^{59)}$. On the other hand, it has been reported that an increase in the HEMA content resulted in a larger polymer network mesh size ${ }^{60)}$. For H10, which has the smallest mesh size among the five polymers, a small amount of CPC micelles is adsorbed to the superficial part of the polymer and most of the adsorbed CPC is rapidly released within a short period. For H30, which has a larger polymer mesh size than $\mathrm{H} 10$, more micellar CPC is adsorbed to the polymer, and a longer release of CPC is possible than from $\mathrm{H} 10$. As for H70 and H90, which have higher water absorbability and larger mesh sizes, a greater amount of CPC is trapped more deeply within the polymer, compared with H10, H30, and H50. However, CPC taken up by these polymers is desorbed less because of strong adsorption through hydrophobic interaction. Among the five polymers fabricated, the polymer particles comprising 50\% HEMA/50\% TMPT have an optimal mesh size for the penetration of micellar CPC and a binding affinity with $\mathrm{CPC}$, showing the largest amounts of release, for the longest period.

Loading of CPC using a pre-mixing method

It has been reported that methacrylate resins to which chlorhexidine powder was added before polymerization exhibit release of the agent for $4-5$ weeks $^{61,62)}$. Through the pre-mixing method, the antimicrobial is dispersed homogeneously inside the polymer and water-diffusion based release can be slow and proceed for longer. The CPC-loaded polymer particles, prepared through mixing CPC powder with the 50\% HEMA/50\% TMPT monomer before polymerization, demonstrated a longer period of CPC release, as expected. The extension of the release period was remarkable compared with immersionloaded H50 polymers, from which release became nondetectable after $72 \mathrm{~h}$. The polymer pre-mixed with $0.5 \%$ CPC demonstrated release of CPC into distilled water for 20 days. For 5\% or 10\% CPC-pre-mixed polymers, the release of CPC continued over 120 days. In addition to the homogenous dispersion of CPC inside the polymer, CPC dissolved in a monomer mixture of HEMA and TMPT does not form micelles as it does in water. Therefore, it is possible that binding of non-micellar CPC to the HEMA/ TMPT polymer by hydrophobic interaction is stronger and therefore long-term release is attained.

Antibacterial activity of CPC-loaded polymer particles CPC has a wide antibacterial spectrum and is effective in inhibiting various oral bacteria. To confirm that CPCpre-mixed polymer particles exhibit antibacterial effects by releasing CPC, agar diffusion tests were conducted. The 0.5, 5, and 10\% CPC-pre-mixed polymer particles demonstrated inhibition against Enterococcus faecalis, Streptococcus mutans, Lactobacillus casei, or Candida

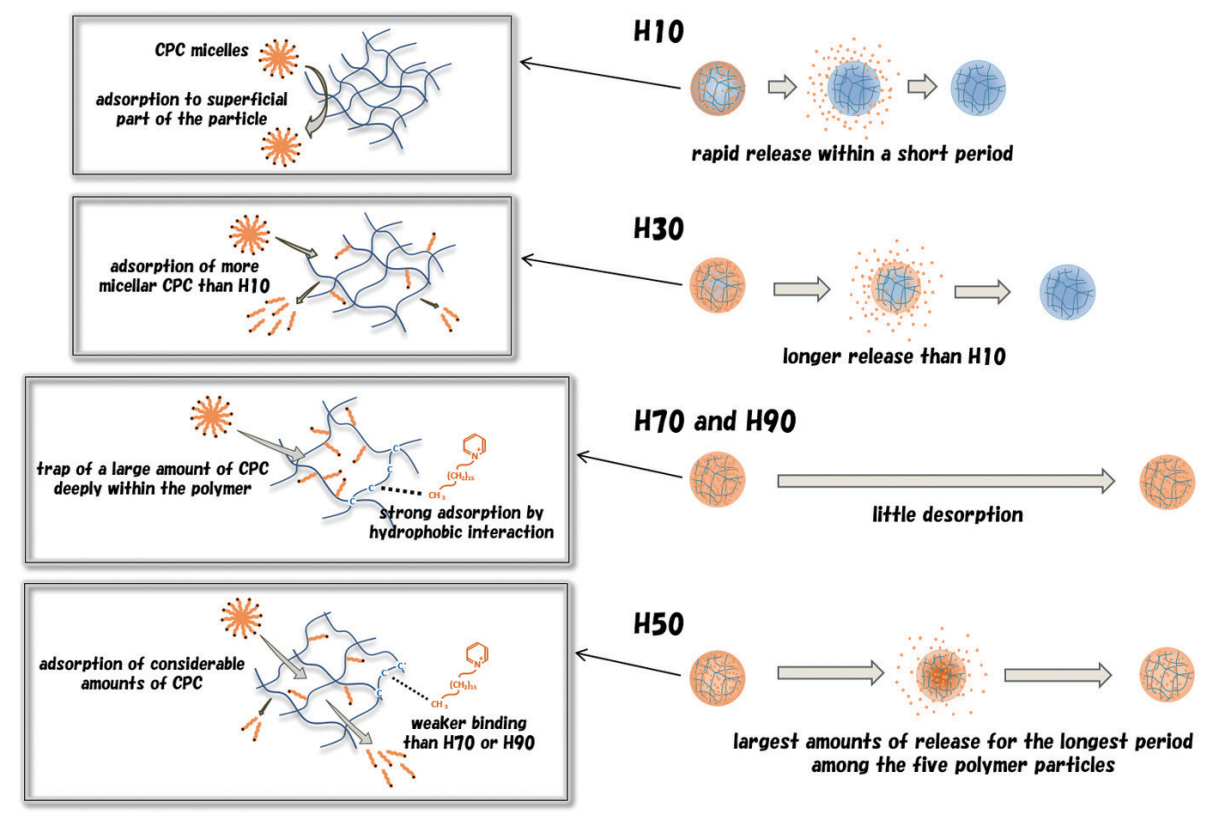

Fig. 7 Schematic diagram of loading of CPC and its release from polyHEMA/TMPT particles. 
Table 2 Size of inhibition zones produced by CPC-pre-mixed polymer particles by agar diffusion tests

\begin{tabular}{|c|c|c|c|}
\hline Bacteria & $\begin{array}{l}0.5 \% \text { CPC-premixed } \\
\text { polymer particles }\end{array}$ & $\begin{array}{l}5 \% \text { CPC-premixed } \\
\text { polymer particles }\end{array}$ & $\begin{array}{c}10 \% \text { CPC-premixed } \\
\text { polymer particles }\end{array}$ \\
\hline Streptococcus mutans NCTC10449 & $1.00 \pm 0.14$ & $4.22 \pm 0.14$ & $4.98 \pm 0.15$ \\
\hline Lactobacillus casei ATCC4646 & $1.37 \pm 0.06$ & $3.57 \pm 0.37$ & $4.40 \pm 0.15$ \\
\hline Enterococcus faecalis SS497 & $0.93 \pm 0.07$ & $2.16 \pm 0.12$ & $4.89 \pm 0.48$ \\
\hline Candida albicans SC5314 & $1.70 \pm 0.22$ & $4.36 \pm 0.57$ & $5.57 \pm 0.23$ \\
\hline
\end{tabular}

The $0.5,5$ or $10 \%$ CPC-pre-mixed polymer particles was filled into wells of an agar plate inoculated with each bacterium. After $72 \mathrm{~h}$ of incubation at $37^{\circ} \mathrm{C}$, production of inhibition zones $(\mathrm{mm})$ was determined.
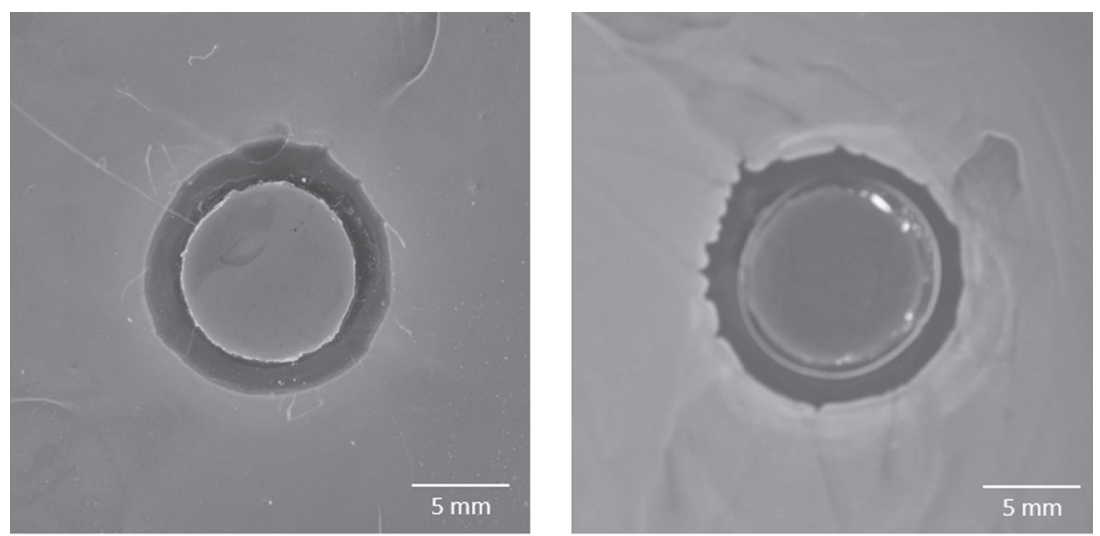

Fig. 8 Exhibition of long-lasting antibacterial effects produced by an experimental endodontic sealer containing CPC-loaded polymer particles.

An experimental sealer containing CPC-pre-mixed polyHEMA/TMPT particles demonstrates inhibition against $E$. faecalis after immersion in water for 14 days (left) or 28 days (right).

albicans. In addition, as the amount of CPC loaded into the polymer was increased, greater inhibition was observed (Table 2).

\section{Sustained release of CPC through recharging}

It was found that smaller molecule CPC is easily taken up by the polyHEMA/TMPT particles. Based on such characteristics, recharge of $\mathrm{CPC}$ to the particles is possible after CPC is released and depleted. As expected, by exposing 50\% HEMA/50\% TMPT polymer particles depleted of CPC, to CPC solutions, recovery of CPC release was possible. This recharging process can be repeated and is applicable for both immersion-loaded and pre-mixing-loaded particles. It is also possible to control the recovery level of $\mathrm{CPC}$ release by adjusting the concentration of the recharging solution and the exposure time. For the 0.5\% CPC-pre-mixed polymer, the release of $\mathrm{CPC}$ above the minimum inhibitory concentrations (MIC) values against Streptococcus mutans, Lactobacillus casei, Enterococcus faecalis or Candida albicans was maintained by a 5 min exposure to a CPC solution at $500 \mu \mathrm{g} / \mathrm{mL}$. Therefore, the combination of pre-mix loading of CPC powder and recharging using a CPC solution is effective to achieve persistent antimicrobial effects with a sustained release of CPC.

\section{Application of CPC-loaded polymer particles to restorative materials}

Currently, an attempt to fabricate a novel endodontic sealer containing CPC-pre-mixed polymer particles is under investigation. To provide endodontic filling materials which exhibit long-lasting antibacterial effects after root canal treatment, an approach to apply these particles which facilitate the long-term release of CPC is likely to be beneficial. The experimental sealers were prepared by combining CPC-pre-mixed polymer particles with a commercial HEMA-based endodontic sealer (MetaSEAL Soft ${ }^{\circledR}$, Sun Medical). This experimental sealer containing CPC-pre-mixed particles exhibited long-lasting antibacterial activity against $E$. faecalis (Fig. 8).

Other applications of this CPC-sustained release system include denture bases or provisional crowns. Resinous materials composed of polymethyl methacrylate 
(PMMA) are prone to plaque accumulation, which is responsible for a variety of clinical problems, including denture stomatitis, periodontal disease, and dental caries. Incorporation of CPC-loaded-polyHEMA/TMPT particles with the ability to recharge CPC has the potential to exhibit sustained antibacterial effects to inhibit biofilm formation.

\section{CONCLUSIONS}

The non-biodegradable polymer particles which we developed are useful as carriers of growth factors or antimicrobials to be combined with restorative materials. Such technology is beneficial for a big leap of restorative materials to next generation with "bio-active" functions. Their application may be further expanded to other materials to provide preventive effects against oral diseases and the promotion of tissue regeneration.

\section{ACKNOWLEDGMENTS}

This work was supported in part by Grants-in-Aid for Scientific Research (numbers JP26293409, JP16K20497) from the Japan Society for the Promotion of Science.

\section{REFERENCES}

1) Imazato S. Bio-active restorative materials with antibacterial effects: new dimension of innovation in restorative dentistry. Dent Mater J 2009; 28: 11-19.

2) Imazato S, Ma S, Chen JH, Xu HH. Therapeutic polymers for dental adhesives: loading resins with bio-active components. Dent Mater 2014; 30: 97-104.

3) Zhao IS, Mei ML, Burrow MF, Lo EC, Chu CH. Prevention of secondary caries using silver diamine fluoride treatment and casein phosphopeptide-amorphous calcium phosphate modified glass-ionomer cement. J Dent 2017; 57: 38-44.

4) Uo M, Wada T, Asakura K. Structural analysis of strontium in human teeth treated with surface pre-reacted glass-ionomer filler eluate by using extended X-ray absorption fine structure analysis. Dent Mater J 2017; 36: 214-221.

5) Ma S, Imazato S, Chen JH, Mayanagi G, Takahashi N, Ishimoto T, Nakano T. Effects of a coating resin containing S-PRG filler to prevent demineralization of root surfaces. Dent Mater J 2012; 31: 909-915.

6) Tezvergil-Mutluay A, Agee KA, Uchiyama T, Imazato S, Mutluay MM, Cadenaro M, Breschi L, Nishitani Y, Tay FR, Pashley DH. The inhibitory effects of quaternary ammonium methacrylates on soluble and matrix-bound MMPs. J Dent Res 2011; 90: 535-540.

7) Mazzoni A, Tjäderhane L, Checchi V, Di Lenarda R, Salo T, Tay FR, Pashley DH, Breschi L. Role of dentin MMPs in caries progression and bond stability. J Dent Res 2015; 94: 241-251.

8) Hashimoto M, Kawai K, Kawakami H, Imazato S. Matrix metalloproteases inhibition and biocompatibility of gold and platinum nanoparticles. J Biomed Mater Res A 2016; 104: 209-217.

9) Mehdawi I, Neel EA, Valappil SP, Palmer G, Salih V, Pratten J, Spratt DA, Young AM. Development of remineralizing, antibacterial dental materials. Acta Biomater 2009; 5: 25252539.

10) Liang K, Weir MD, Xie X, Wang L, Reynolds MA, Li J, Xu HH. Dentin remineralization in acid challenge environment via PAMAM and calcium phosphate composite. Dent Mater
2016; 32: 1429-1440.

11) Prati C, Gandolfi MG. Calcium silicate bioactive cements: Biological perspectives and clinical applications. Dent Mater 2015; 31: 351-370.

12) Nagayasu-Tanaka T, Anzai J, Takaki S, Shiraishi $\mathrm{N}$, Terashima A, Asano T, Nozaki T, Kitamura M, Murakami S. Action mechanism of fibroblast growth factor-2 (FGF-2) in the promotion of periodontal regeneration in beagle dogs. PLoS One 2015; 10: e0131870.

13) Ikada Y, Tabata Y. Protein release from gelatin matrices. Adv Drug Deliv Rev 1998; 31: 287-301.

14) Coviello T, Matricardi P, Marianecci C, Alhaique F. Polysaccharide hydrogels for modified release formulations. J Control Release 2007; 119: 5-24.

15) Lin CC, Anseth KS. PEG hydrogels for the controlled release of biomolecules in regenerative medicine. Pharm Res 2009; 26: 631-643.

16) Brazel CS, Peppas NA. Dimensionless analysis of swelling of hydrophilic glassy polymers with subsequent drug release from relaxing structures. Biomaterials 1999; 20: 721-732.

17) Zhang B, Lalani R, Cheng F, Liu Q, Liu L. Dual-functional electrospun poly(2-hydroxyethyl methacrylate). J Biomed Mater Res A 2011; 99: 455-466

18) Trigo RM, Blanco MD, Teijon JM, Sastre R. Anticancer drug, ara-C, release from pHEMA hydrogels. Biomaterials 1994; 15: 1181-1186.

19) Defrere $S$, Mestagdt M, Riva R, Krier F, Van Langendonckt A, Drion P, Jérôme C, Evrard B, Dehoux JP, Foidart JM, Donnez J. In vivo biocompatibility of three potential intraperitoneal implants. Macromol Biosci 2011; 11: 1336-1345.

20) Kitagawa H, Takeda K, Kitagawa R, Izutani N, Miki $\mathrm{S}$, Hirose N, Hayashi M, Imazato S. Development of sustained antimicrobial-release systems using poly(2hydroxyethylmethacrylate)/trimethylolpropane trimethacrylate hydrogels. Acta Biomater 2014; 10: 4285-4295.

21) Takeda K, Kitagawa H, Tsuboi R, Kiba W, Sasaki JI, Hayashi $\mathrm{M}$, Imazato S. Effectiveness of non-biodegradable poly(2hydroxyethyl methacrylate)-based hydrogel particles as a fibroblast growth factor-2 releasing carrier. Dent Mater 2015; 31: 1406-1414.

22) Geurtsen W. Biocompatibility of resin-modified filling materials. Crit Rev Oral Biol Med 2000; 11: 333-355.

23) Pashley EL, Zhang Y, Lockwood PE, Rueggeberg FA, Pashley DH. Effects of HEMA on water evaporation from waterHEMA mixtures. Dent Mater 1998; 14: 6-10.

24) Munoz-Pinto DJ, Grigoryan B, Long J, Grunlan M, Hahn MS. An approach for assessing hydrogel hydrophobicity. J Biomed Mater Res A 2012; 100: 2855-2860.

25) Pallicer JM, Pous-Torres S, Sales J, Roses M, Rafols C, Bosch E. Determination of the hydrophobicity of organic compounds measured as $\log \mathrm{P}(\mathrm{o} / \mathrm{w})$ through a new chromatographic method. J Chromatogr A 2010; 1217: 3026-3037.

26) Jang J, WS Go. Continuous photografting of HEMA onto polypropylene fabrics with benzophenone photoinitiator. Fiber Polym 2008; 9: 375-379.

27) Laverty G, Gorman SP, Gilmore BF. Antimicrobial peptide incorporated poly(2-hydroxyethyl methacrylate) hydrogels for the prevention of Staphylococcus epidermidis-associated biomaterial infections. J Biomed Mater Res A 2012; 100: 1803-1814.

28) Nugenta MA, Iozzo RV. Fibroblast growth factor-2. Int $J$ Biochem Cell B 2000; 32: 115-120.

29) Wang YJ, Shahrokh Z, Vemuri S, Eberlein G, Beylin I, Busch M. Characterization, stability, and formulations of basic fibroblast growth factor. Pharm Biotechnol 1996; 9: 141-180.

30) Gospodarowicz D, Ferrara N, Schweigerer L, Neufeld G. Structural characterization and biological functions of fibroblast growth factor. Endocr Rev 1987; 8: 95-114.

31) Wang JS. Basic fibroblast growth factor for stimulation of 
bone formation in osteoinductive or conductive implants. Acta Orthop Scand Suppl 1996; 269: 1-33.

32) Morito A, Kida Y, Suzuki K, Inoue K, Kuroda N, Gomi K, Arai T, Sato T. Effects of basic fibroblast growth factor on the development of the stem cell properties of human dental pulp cells. Arch Histol Cytol 2009; 72: 51-64.

33) Yamachika E, Tsujigiwa H, Matsubara M, Hirata Y, Kita K, Takabatake K, Mizukawa N, Kaneda Y, Nagatsuka H, Iida S. Basic fibroblast growth factor supports expansion of mouse compact bone-derived mesenchymal stem cells (MSCs) and regeneration of bone from MSC in vivo. J Mol Histol 2012; 43: 223-233.

34) Cartland SP, Genner SW, Zahoor A, Kavurma MM. Comparative evaluation of TRAIL, FGF-2 and VEGF-Ainduced angiogenesis in vitro and in vivo. Int $\mathrm{J}$ Mol Sci 2016; 17: E2025.

35) Kitamura M, Akamatsu M, Kawanami M, Furuichi Y, Fujii T, Mori M, Kunimatsu K, Shimauchi H, Ogata Y, Yamamoto M, Nakagawa T, Sato S, Ito K, Ogasawara T, Izumi Y, Gomi K, Yamazaki K, Yoshie H, Fukuda M, Noguchi T, Takashiba S, Kurihara H, Nagata T, Hamachi T, Maeda K, Yokota M, Sakagami R, Hara Y, Noguchi K, Furuuchi T, Sasano T, Imai E, Ohmae M, Koizumi H, Watanuki M, Murakami S. Randomized placebo-controlled and controlled non-inferiority phase III trials comparing trafermin, a recombinant human fibroblast growth factor 2, and enamel matrix derivative in periodontal regeneration in intrabony defects. J Bone Miner Res 2016; 31: 806-814.

36) Striemer CC, Gaborski TR, McGrath JL, Fauchet PM. Charge- and size-based separation of macromolecules using ultrathin silicon membranes. Nature 2007; 445: 749-753.

37) Torabinejad M, Chivian N. Clinical applications of mineral trioxide aggregate. J Endod 1999; 25: 197-205.

38) Parirokh M, Torabinejad M. Mineral trioxide aggregate: a comprehensive literature review -Part III: Clinical applications, drawbacks, and mechanism of action. J Endod 2010; 36: 400-413.

39) Unver S, Onay EO, Ungor M. Intentional re-plantation of a vertically fractured tooth repaired with an adhesive resin. Int Endod J 2011; 44: 1069-1078.

40) Sugaya T, Kawanami M, Noguchi H, Kato H, Masaka N. Periodontal healing after bonding treatment of vertical root fracture. Dent Traumatol 2001; 17: 174-179.

41) Hayashi M, Kinomoto Y, Takeshige F, Ebisu S. Prognosis of intentional replantation of vertically fractured roots reconstructed with dentin-bonded resin. J Endod 2004; 30: 145-148.

42) Nizam N, Kaval ME, Gürlek Ö, Atila A, Çalışkan MK. Intentional replantation of adhesively reattached vertically fractured maxillary single-rooted teeth. Int Endod J 2016; 49: 227-236.

43) Otani K, Sugaya T, Tomita M, Hasegawa Y, Miyaji H, Tenkumo T, Tanaka S, Motoki Y, Takanawa Y, Kawanami M. Healing of experimental apical periodontitis after apicoectomy using different sealing materials on the resected root end. Dent Mater J 2011; 30: 485-492.

44) Wang P, Wang S, Ni L. The combination of a mineral trioxide aggregate and an adhesive restorative approach to treat a crown-root fracture coupled with lateral root perforation in a mandibular second molar: a case report. Oper Dent 2009; 34: 497-502.

45) Tanaka Y, Sugaya T, Tanaka S, Kawanami M. Long-term durability of root-end sealing with 4-META/MMA-TBB resin. Dent Mater J 2004; 23: 453-456.
46) Imazato S, Horikawa D, Nishida M, Ebisu S. Effects of monomers eluted from dental resin restoratives on osteoblastlike cells. J Biomed Mater Res B Appl Biomater 2009; 88: 378-386.

47) Imazato S, Horikawa D, Takeda K, Kiba W, Izutani N, Yoshikawa R, Hayashi M, Ebisu S, Nakano T. Proliferation and differentiation potential of pluripotent mesenchymal precursor C2C12 cells on resin-based restorative materials. Dent Mater J 2010; 29: 341-346.

48) Elkhadem A, Mickan S, Richards D. Adverse events of surgical extrusion in treatment for crown-root and cervical root fractures: a systematic review of case series/reports. Dent Traumatol 2014; 30: 1-14.

49) Kitagawa H, Takeda K, Tsuboi R, Hayashi M, Sasaki J, Imazato S. Influence of polymerization properties of 4-META/ MMA-based resin on the activity of fibroblast growth factor-2. Dent Mater J 2017, in press.

50) Imazato S. Antibacterial properties of resin composites and dentin bonding systems. Dent Mater 2003; 19: 449-457.

51) Baker PJ, Coburn RA, Genco RJ, Evans RT. The in vitro inhibition of microbial growth and plaque formation by surfactant drugs. J Periodontal Res 1978; 13: 474-485.

52) Jones DS, Schep LJ, Shepherd MG. The effect of cetylpyridinium chloride (CPC) on the cell surface hydrophobicity and adherence of Candida albicans to human buccal epithelial cells in vitro. Pharm Res 1995; 12: 18961900.

53) Otten MP, Busscher HJ, van der Mei HC, Abbas F, van Hoogmoed CG. Retention of antimicrobial activity in plaque and saliva following mouthrinse use in vivo. Caries Res 2010; 44: 459-464.

54) Rioboo M, García V, Serrano J, O’Connor A, Herrera D, Sanz M. Clinical and microbiological efficacy of an antimicrobial mouth rinse containing $0.05 \%$ cetylpyridinium chloride in patients with gingivitis. Int J Dent Hyg 2012; 10: 98-106.

55) Fathilah AR, Himratul-Aznita WH, Fatheen AR, Suriani KR. The antifungal properties of chlorhexidine digluconate and cetylpyridinium chloride on oral Candida. J Dent 2012; 40: 609-615

56) Roettger BF, Ladisch MR. Hydrophobic interaction chromatography. Biotechnol Adv 1989; 7: 15-29.

57) Wilson MJ, Haggart CL, Gallagher SP, Walsh D. Removal of tightly bound endotoxin from biological products. J Biotechnol 2001; 88: 67-75.

58) Anachkov SE, Danov KD, Basheva ES, Kralchevsky PA, Ananthapadmanabhan KP. Determination of the aggregation number and charge of ionic surfactant micelles from the stepwise thinning of foam films. Adv Colloid Interface Sci 2012; 183-184: 55-67.

59) Deriszadeh A, Husein MM, Harding TG. Produced water treatment by micellar-enhanced ultrafiltration. Environ Sci Technol 2010; 44: 1767-1772.

60) Canal T, Peppas NA. Correlation between mesh size and equilibrium degree of swelling of polymeric networks. J Biomed Mater Res 1989; 23: 1183-1193.

61) Pallan S, Furtado Araujo MV, Cilli R, Prakki A. Mechanical properties and characteristics of developmental copolymers incorporating catechin or chlorhexidine. Dent Mater 2012; 28: 687-694.

62) Hiraishi N, Yiu CK, King NM, Tay FR. Chlorhexidine release and antibacterial properties of chlorhexidine-incorporated polymethyl methacrylate-based resin cement. J Biomed Mater Res B Appl Biomater 2010; 94: 134-140. 